\title{
Neonatal Hypertension, AE
}

National Cancer Institute

\section{Source}

National Cancer Institute. Neonatal Hypertension, AE. NCI Thesaurus. Code C154929.

An adverse event in a newborn characterized by abnormally high blood pressure. 